\title{
The effect of alkaloids present in blue lupine (Lupinus angustifolius) seeds on the growth rate, selected biochemical blood indicators and histopathological changes in the liver of rats
}

\author{
Maria Stanek ${ }^{1}$, Tadeusz Rotkiewicz ${ }^{2}$, Wiesław Sobotka ${ }^{1}$, Jacek Bogusz ${ }^{1}$, \\ Iwona Otrocka-Domagała ${ }^{2}$, Agnieszka Rotkiewicz ${ }^{3}$
}

\begin{abstract}
University of Warmia and Mazury in Olsztyn, ${ }^{1}$ Faculty of Animal Bioengineering, Department of Animal Nutrition and Fodder Science, ${ }^{2}$ Faculty of Veterinary Medicine, Department of Pathological Anatomy, ${ }^{3}$ Faculty of Law and Administration, Department of Administrative Procedure and Administrative Court Proceedings, Olsztyn, Poland
\end{abstract}

Received February 14, 2014

Accepted October 22, 2014

\begin{abstract}
The objective of this study was to determine the effect of alkaloids present in blue lupine (Lupinus angustifolius) seeds on the growth rate, selected indicators of carbohydrate and lipid metabolism, and liver morphology in rats. The experimental material comprised 32 Wistar rats at around 3 weeks of age, with an initial body weight of $81 \mathrm{~g}$. During a 28-day feeding trial, the rats were fed diets containing the seeds of three blue lupine cultivars, Baron, Zeus and Wersal, with different alkaloid concentrations $(0.36,0.41,0.56 \mathrm{mg} / \mathrm{kg}$, respectively). Diets containing the seeds of three blue lupine cultivars reduced the feed intake and significantly limited the growth rate of experimental rats, compared to the control group. Lupine alkaloids had no effect on the serum concentrations of glucose and total cholesterol in rats, whereas elevated triglyceride concentrations were noted in experimental groups, relative to the control group. Diets containing the seeds of blue lupine cultivars Zeus and Wersal induced changes in alanine transaminase activity. A histopathological analysis of the liver revealed parenchymatous degeneration, which was more advanced in rats fed diets with the seeds of blue lupine cultivars Zeus and Wersal than in the control group, and congestion of portal vessels, which was more severe in rats fed the seeds of blue lupine cultivars Baron and Zeus.
\end{abstract}

Feed intake, weight gains, protein efficiency ratio (PER), metabolism, pathomorphology

Recent years have witnessed a growing interest in blue lupine (Lupinus angustifolius) seeds as a component of the human diet and diets for growing-finishing pigs, broiler chickens and laying hens, and a local source of vegetable protein that provides numerous functional compounds and can partially replace imported protein materials. Lupine seeds contain proteins that are high in lysine and arginine (Stanek et al. 2006; Crepon et al. 2010; Stanek et al. 2012), and their nutritional value is comparable with that of soybean protein. The lipid fraction of lupine seeds contains natural antioxidants, tocopherols, whose content is correlated with the concentrations of polyunsaturated fatty acids (LampartSzczapa and Łoza 2007). Due to the desirable composition of their lipid fraction, lupine seeds exert hypocholesterolaemic effects (Rahman 2005). Lupine seeds also contain antinutritional compounds such as polyphenols, oligosaccharides, fibre and, most importantly, toxic quinolizidine alkaloids, including bicyclic lupinine, tricyclic angustifoline, tetracyclic lupanine, sparteine, 13-hydroxylupanine, and indole gramine, which may have adverse effects on animals by inducing changes in their nervous, digestive, and reproductive systems (Birk 1993; Bañuelos Pineda et al. 2005). Alkaloids are responsible for the bitter taste of feed, which often contributes to reduced feed intake, and they can affect the nutrient metabolism in rats. Lupine oligosaccharides, once considered nutritionally undesirable, have been shown to deliver health benefits by promoting the development of beneficial

Address for correspondence:

Wiesław Sobotka, Professor

Department of Animal Nutrition and Fodder Science

University of Warmia and Mazury in Olsztyn

Oczapowskiego 5, 10-719 Olsztyn, Poland
Phone: +485233379
Fax +48 5233519
E-mail: wieslaw.sobotka@uwm.edu.pl
http://actavet.vfu.cz/ 
gut microflora and stimulating metabolic processes in the intestines of rats and piglets (Hedeman et al. 2006; Juśkiewicz et al. 2006). Due to their high nutritional value, blue lupine seeds can be used as a component of animal diets. However, their optimal dietary inclusion levels have not been defined to date. The concentrations of alkaloids, the antinutritional factors found in lupine seeds, have been considerably reduced through breeding programs, yet they can still pose a potential threat to animal health (De Cortes-Sánchez et al. 2005; Maknickiene et al. 2013).

In view of the fact that lupine seeds can be used as a vegetable protein source in diets for monogastric animals, particularly pigs, the aim of this study was to determine the response of rats (model animals for pigs) to alkaloids contained in blue lupine seeds, based on their growth rate, selected biochemical processes, and liver morphology.

\section{Materials and Methods}

The experiment was performed on 32 male Wistar rats divided into 4 groups. The animal protocol used in this study had been approved by the Local Institutional Animal Care and Use Committee (Resolution No. 07/2011), and the study was carried out in accordance with the EU Directive 2010/63/EU on the protection of animals used for scientific purposes. Animals at around 3 weeks of age, with initial body weights of approximately $81 \mathrm{~g}$, were selected for experimental groups so as not to exceed a $10 \mathrm{~g}$ difference in body weight between individuals within the group, and a $5 \mathrm{~g}$ difference in the total body weight per group. Rats from the same litter were allocated to different groups. The animals were placed in individual metabolism cages under constant microclimatic conditions: $12 \mathrm{~h}$ light, temperature of $21-23{ }^{\circ} \mathrm{C}$, relative air humidity of $50-60 \%$, air exchange $\times 10-15$. The seeds of blue lupine cultivars Baron, Zeus and Wersal, with different alkaloid concentrations (Table 1), were added to semi-synthetic diets as a substitute for soybean meal. All diets were composed of starch, corn meal, soybean oil, mineral premix, and vitamin premix. The differences in alkaloid concentrations in diets resulted from different alkaloid concentrations in the analyzed blue lupine cultivars (Table 2). The protein content of diets was approximately $10 \%$, and it met the protein requirements for rats (NRC 1995). The animals had free access to feed and water. The feed intake and growth rate of rats were determined on a daily basis over the 28-day experiment.

Table 1. Chemical composition of lupine seeds $(\mathrm{g} / \mathrm{kg})$.

\begin{tabular}{lccc}
\hline \multirow{2}{*}{ Specification } & \multicolumn{3}{c}{ Blue lupine cultivars } \\
\cline { 2 - 4 } Total protein & 333.2 & Zeus & Wersal \\
Crude fat & 48.7 & 327.0 & 316.7 \\
N-free extracts & 409.3 & 54.6 & 49.8 \\
Crude fibre & 167.5 & 419.2 & 428.3 \\
\hline Oligosaccharides & 69.7 & 167.0 & 164.8 \\
& & 63.2 & 73.6 \\
Sucrose & 28.26 & Composition (\%) & \\
Raffinose & 14.20 & 26.11 & 32.07 \\
Stachyose & 42.05 & 16.61 & 13.86 \\
Verbascose & 15.49 & 43.20 & 38.45 \\
Alkaloids & 0.36 & 14.07 & 15.62 \\
& & 0.41 & 0.56 \\
Lupanine & 70.20 & Composition $(\%)$ & 65.60 \\
Isolupanine & 8.10 & 62.40 & 7.70 \\
Angustifoline & 8.70 & 6.60 & 9.70 \\
Hydroxylupanine & 9.50 & 10.60 & 11.80 \\
Tetrarombifoline & 2.50 & 14.40 & 3.70 \\
Isoangustifoline & 1.00 & 4.10 & 1.50 \\
\hline
\end{tabular}

After 28 days, at the end of the experiment, the animals were anesthetized and blood was sampled from the hepatic portal vein, the concentrations of glucose, triacylglycerols (TG), total cholesterol (TC), and the activity of 
Table 2. Composition of experimental diets, \%.

\begin{tabular}{lcccc}
\hline \multirow{2}{*}{ Specification } & \multicolumn{3}{c}{ Group } \\
\cline { 2 - 5 } & Control & Baron & Zeus & Wersal \\
\hline Soybean meal & 17.4 & - & - & - \\
Blue lupine & - & 25.8 & 26.6 & 27.1 \\
Starch & 56.4 & 48.0 & 47.2 & 46.7 \\
Corn meal & 17.7 & 17.7 & 17.7 & 17.7 \\
Mineral premix & 3.5 & 3.5 & 3.5 & 3.5 \\
Vitamin premix & 2.0 & 2.0 & 2.0 & 2.0 \\
Soybean oil & 3.0 & 3.0 & 3.0 & 3.0 \\
\hline Total protein, g/kg & 100.4 & 105.7 & 102.5 & 100.4 \\
Alkaloids, g/kg & - & 0.09 & 0.11 & 0.15 \\
\hline
\end{tabular}

alanine transaminase (ALT) and aspartate transaminase (AST) were determined in the Cobas C-501 analyzer using Roche Diagnostics (Poland) reagents. After euthanasia (Close et al. 1997), liver sections were collected from five rats per group for a histopathological analysis. The sections were fixed in $10 \%$ neutral-buffered formalin, and were embedded in paraffin according to the standard histological procedure. Microtome sections, $4 \mathrm{~m}$ thick, were stained with haematoxylin and eosin (HE) and periodic acid-Schiff (PAS) reagent (McManus) to determine the presence of glycogen in hepatocytes, and Gomori methenamine silver to reveal changes in reticular and collagen fibres (Zawistowski 1975; Rotkiewicz 2004).

The alkaloid content of lupine seeds was measured using the Varian 450-GC gas chromatograph with 220-MS mass spectrometer (VF-5ms capillary column, length - $30 \mathrm{~m}$, to $5 \%$ phenyl/95\% dimethylpolysiloxane low bleed).

The obtained results were verified statistically by one-way ANOVA. The statistical significance of differences between the mean values of the analyzed indicators in experimental groups vs. the control group was estimated by Duncan's multiple range test, using STATISTICA PL version 10.0 software. The coefficient correlation (r) was calculated between the concentration of alkaloids and the weight of the liver.

\section{Results}

Lupine-based diets affected the feed intake in experimental groups. Over 28 days of the growth trial, feed intake reached $450.2 \mathrm{~g}$ in the control group, and it was approximately $150 \mathrm{~g}$ lower in experimental groups (Table 3 ). The initial body weights of rats were similar, whereas their final body weights were over $50 \mathrm{~g}$ lower in all experimental groups, compared to the control group. Differences in the feed intake, body weight gains and final body weights between the control group and experimental groups were significant $(P<0.01)$.

Table 3. Body weight gains of rats, feed intake and protein efficiency ratio.

\begin{tabular}{|c|c|c|c|c|c|}
\hline \multirow{2}{*}{ Specification } & \multicolumn{4}{|c|}{ Group } & \multirow{2}{*}{ SEM } \\
\hline & Control & Baron & Zeus & Wersal & \\
\hline Initial body weight, $\mathrm{g}$ & 80.6 & 80.7 & 80.8 & 80.8 & 0.687 \\
\hline Feed intake, $\mathrm{g} / 28$ days & $450.2^{\mathrm{A}}$ & $315.6^{\mathrm{B}}$ & $310.1^{\mathrm{B}}$ & $300.9^{\mathrm{B}}$ & 12.535 \\
\hline Final body weight, $g$ & $188.6^{\mathrm{A}}$ & $135.2^{\mathrm{B}}$ & $134.1^{\mathrm{B}}$ & $130.4^{\mathrm{B}}$ & 4.894 \\
\hline Body weight gain, $\mathrm{g} / 28$ days & $108.0^{\mathrm{A}}$ & $54.5^{\mathrm{B}}$ & $53.3^{\mathrm{B}}$ & $49.6^{\mathrm{B}}$ & 4.768 \\
\hline \multicolumn{6}{|l|}{ Feed intake, g/day/animal } \\
\hline Days 1-14 & $14.28^{\mathrm{A}}$ & $9.56^{\mathrm{B}}$ & $9.61^{\mathrm{B}}$ & $9.77^{\mathrm{B}}$ & 0.322 \\
\hline Days $15-28$ & $16.94^{\mathrm{A}}$ & $12.90^{\mathrm{B}}$ & $12.32^{\mathrm{B}}$ & $11.70^{\mathrm{B}}$ & 0.271 \\
\hline PER & $2.39^{\mathrm{A}}$ & $1.62^{\mathrm{B}}$ & $1.67^{\mathrm{B}}$ & $1.62^{\mathrm{B}}$ & 0.068 \\
\hline
\end{tabular}

${ }_{\mathrm{A}, \mathrm{B}} P \geq 0.01, \quad \mathrm{SEM}$ - standard error of the mean, PER - protein efficiency ration 
Table 4. Serum concentrations of glucose, triacylglycerols, total cholesterol and activity of alanine transaminase and aspartate transaminase in rats.

\begin{tabular}{lcccccc}
\hline \multirow{2}{*}{ Specification } & \multicolumn{5}{c}{ Group } & \multirow{2}{*}{ SEM } \\
\cline { 2 - 5 } & Reference ranges $^{*}$ & Control & Baron & Zeus & Wersal & \\
\hline Glucose, mmol/1 & $(8.0-13.4)$ & 11.02 & 12.28 & 13.10 & 13.00 & 0.408 \\
TG, mmol/1 & $(0.41-1.65)$ & $1.14^{\mathrm{B}}$ & $1.56^{\mathrm{A}}$ & $1.68^{\mathrm{A}}$ & $1.77^{\mathrm{A}}$ & 0.083 \\
TC, mmol/1 & $(0.8-1.82)$ & 2.57 & 2.32 & 2.58 & 2.51 & 0.049 \\
ALT, U/l & $(24-73)$ & $25.9^{\mathrm{a}}$ & 20.5 & $18.9^{\mathrm{b}}$ & $18.7^{\mathrm{b}}$ & 1.038 \\
AST, U/l & $(45-107)$ & 134.4 & 148.7 & 132.9 & 134.3 & 5.137 \\
\hline
\end{tabular}

A,B $P \geq 0.01$ a,b $P \geq 0.05, \quad$ SEM - standard error of the mean

TG - triacylglycerols, TC - total cholesterol, ALT - activity of alanine transaminase, AST - activity of aspartate transaminase, *Liberati et al. (2004)

The protein efficiency ratio (PER) of lupine-based diets ranged from 1.62 to 1.67, and it was lower than that determined for the control diet that contained soybean meal (2.39).

In most cases, experimental diets led only to minor, non-significant differences in biochemical blood indicators between groups. Serum glucose concentrations reached $11.02 \mathrm{mmol} / \mathrm{l}$ in the control group, and they were only approximately $1.26 \mathrm{mmol} / \mathrm{l}$ lower than the values noted in experimental groups (Table 4). However, TG concentrations were significantly higher in experimental group rats $(1.56,1.68$ and $1.77 \mathrm{mmol} / \mathrm{l})$, compared to the control group $(1.14 \mathrm{mmol} / \mathrm{l})$. The ALT activity was determined at $25.9 \mathrm{U} / 1$ in the control group. Significant differences in ALT activity were found between the control group and experimental group rats fed diets containing lupine seeds of cultivars Zeus and Wersal, which have higher alkaloid concentrations.

Liver weight varied considerably between groups (Table 5). Control group rats were characterized by the highest liver weight $(6.19 \mathrm{~g})$, and lower liver weight was noted in rats fed lupine-based diets.

Table 5. Morphological changes in the livers of rats.

\begin{tabular}{lcccc}
\hline Specification & \multicolumn{3}{c}{ Group } \\
\cline { 2 - 5 } & Control & Baron & Zeus & Wersal \\
\hline Liver weight, g & $6.19^{\mathrm{Aa}}$ & $5.35^{\mathrm{b}}$ & $5.24^{\mathrm{b}}$ & $4.78^{\mathrm{B}}$ \\
Livers affected by changes & & & \\
Increased amounts of glycogen in hepatocytes & 3 & 4 & 2 & 2 \\
Parenchymatous degeneration of hepatocytes & 1 & 2 & 4 & 3 \\
Vacuolar degeneration of hepatocytes & 2 & 2 & 2 & 2 \\
Congestion of portal vessels & 3 & 5 & 3 \\
Congestion of central veins in a few hepatic lobules & 1 & 4 & 4 & 3 \\
Capillary congestion in hepatic lobules & 2 & 4 & & 2 \\
\hline
\end{tabular}

A,B $P \geq 0.01^{\text {a,b }} P \geq 0.05$

Table 6. Correlations between dietary alkaloids concentration and liver weight

\begin{tabular}{lcc}
\hline $\mathrm{X}$ & $\mathrm{Y}$ & Correlation coefficient $\mathrm{r}$ \\
\hline Alkaloids concentration & Liver weight & $-0.548^{*}$ \\
\hline
\end{tabular}

*significant at $P \leq 0.05$ 
The liver weight of rats fed diets with blue lupine seeds was negatively correlated with alkaloid concentrations, and it decreased with increasing dietary alkaloid concentrations (Table 6)

The experimental factor affected also morphological changes in the livers of rats. Large numbers of glycogen granules were present in the livers of 3 control group rats, in the livers of 4 rats fed a diet with lupine seeds of cultivar Baron, and in the livers of 2 rats fed diets with lupine seeds of cultivars Zeus and Wersal. The number of PAS-positive granules was higher in the hepatocytes of control group rats and rats fed lupine seeds of cultivar Baron. A low number of PAS-positive granules were noted in the hepatocytes of rats fed lupine seeds of cultivars Zeus and Wersal. Individual lobules with a higher number of PAS-positive granules were observed in only two rats from the group fed lupine seeds of cultivar Zeus, and in two animals from the group fed lupine seeds of cultivar Wersal. Parenchymatous degeneration of hepatocytes was observed around the central and intermediate hepatic veins of rats fed lupine-supplemented diets (Plate I, II, Figs. 2, 3, 4). Many hepatocytes showed signs of vacuolar degeneration, and some hepatocytes suffered from adipose degeneration. Retrogressive changes were accompanied by congestion of portal vessels, which was observed in all experimental groups and was more severe in the livers of rats fed the seeds of blue lupine cultivars Baron and Zeus. Congestion of intralobular veins was observed in numerous hepatic lobules in rats fed lupine seeds of cultivars Baron, Zeus and Wersal, and in a few lobules in control group animals where congestion was weaker (Plate I, Fig. 1). The Gomori silver stain revealed well-developed reticular and collagen fibres in control group animals and rats fed lupine seeds of cultivars Baron, Zeus and Wersal.

\section{Discussion}

Blue lupine seeds had an adverse effect on feed intake, which resulted in lower body weight gains of rats. Feed intake determined for the entire experimental period was approximately $30 \%$ lower in rats fed lupine-supplemented diets, primarily due to reduced feed consumption at the beginning of the experiment. It seems that rats with relatively low body weights were more sensitive to the bitter taste of lupine alkaloids, since Sobotka et al. (2013) observed a weaker response to dietary alkaloids in rats whose initial body weights were over $20 \mathrm{~g}$ higher than in the present study. The adjustment period was identical in both experiments. The cited authors demonstrated that blue lupine seeds present in the diet had no influence on feed intake and only non-significantly decreased the growth rate of rats.

In the current experiment, reduced feed intake in experimental groups could also result from the fact that the adjustment period was too short to allow the animals to adapt to the toxic compounds in the diet.

According to Butler et al. (1996) and Robbins et al. (1996), alkaloids may be responsible for reduced feed intake in rats, in particular during the first two weeks of feeding blue lupine seeds, as rats are sensitive to their presence. In the cited study, treatment-related effects were observed at daily intakes of lupine alkaloids exceeding $400 \mathrm{mg} / \mathrm{kg}$ body weight, and changes in morphological blood indicators were noted at alkaloid concentrations of $500 \mathrm{mg} / \mathrm{kg}$ body weight.

Adverse effects of lupine alkaloids on pigs were reported by Rotkiewicz et al. (2007). Diets supplemented with $28 \%$ blue lupine seeds $(0.56 \mathrm{~g} / \mathrm{kg}$ alkaloids $)$ caused deformation or atrophy of intestinal villi in the duodenum and jejunum of pigs, and an increase in the counts of intraepithelial lymphocytes and eosinophils in the intestines. Immune system stimulation and proliferation of glandular cells and hepatocytes were also observed.

In the present study, lower feed and dietary protein intake in experimental groups led to an over 30\% decrease in PER in rats fed experimental diets, compared with rats fed the control diet containing casein. 
The considerably lower body weight gains of rats in experimental groups resulted from alkaloid concentrations in the diets $(0.09-0.15 \mathrm{~g}$ per $\mathrm{kg}$ feed), which were too high for rats weighing $80 \mathrm{~g}$, and reduced their growth rate by approximately $50 \%$.

Serum glucose concentrations were higher in the experimental rats than those in the control group animals, but the differences were not significant, and the values remained within the reference ranges.

The noted increase in TG concentrations suggests that oligosaccharides present in lupine-based diets did not impede the access of digestive enzymes to nutrients and did not impair their absorption (Saini 1989; Gdala and Buraczewska 1996). Certain functional gastrointestinal disorders could be observed shortly after the administration of oligosaccharides, whereas the beneficial influence of those compounds (stimulation of the growth and activity of desirable bacteria, control of the growth of undesirable bacteria, beneficial changes in gut metabolism, control of gas production) could take place after the adjustment period (Juśkiewicz et al. 2006).

An analysis of the activity levels of peripheral blood enzymes, ALT and AST, did not reveal any significant physiological disorders in rats. Only lower ALT activity, in particular in rats fed diets with lupine seeds of cultivars Wersal and Zeus (with higher alkaloid concentrations), could point to certain disorders of amino acid catabolism in the liver. This could be also a consequence of too low feed intake.

Congestion of portal vessels and central veins in the liver, observed in our study, could occur during blood sampling from the hepatic vein, due to heart weakness and slower blood flow resulting from the use of anaesthetics and further procedures leading to euthanasia. However, it should be noted that congestion of portal vessels and central veins occurred primarily in rats fed blue lupine seeds of cultivars Baron and Zeus, and to a lower extent in animals fed lupine seeds of cultivar Wersal and control group rats. Congestion of intralobular capillaries, noted in rats fed lupine seeds of cultivars Baron, Zeus and Wersal, was part of hepatic adaptation to the process of detoxifying toxic compounds present in feed, and was associated with parenchymatous and vacuolar degeneration of hepatocytes. Liver degeneration is a manifestation of damage to cell organelles (Madej and Rotkiewicz 2006).

Parenchymatous degeneration of hepatocytes could appear during the adjustment process when rats were fed diets with blue lupine seeds, due to the absorption of toxic substances that contribute to mitochondrial swelling and the formation of cytoplasmic vacuoles in hepatocytes. The macroscopic and microscopic picture of the above changes corresponds to parenchymatous degeneration, but this is part of an adaptive response and the symptoms usually subside in a short time (Rotkiewicz et al. 2007). It seems that a four-week experimental period was too short for the liver to effectively eliminate toxic alkaloids. Despite the inclusion of blue lupine seeds in rat diets at $25.8-27.1 \%$, the experimental diets contained relatively low alkaloid concentrations. However, rats with low body weights responded negatively to the presence of alkaloids in feed. Alkaloids also led to more severe liver lesions such as vacuolar degeneration, encountered in several cases in rats fed lupine seeds of cultivar Wersal (with the highest alkaloid content). The above degenerative changes, including congestion of intralobular capillaries, parenchymatous and vacuolar degeneration of hepatocytes, were reversible, as indicated by increased amounts of glycogen in hepatocytes, particularly visible in liver sections collected from rats fed lupine seeds of cultivar Baron (with the lowest alkaloid content). Increased glycogen concentrations in hepatocytes contribute to the formation of high-energy bonds (ATP), positively affect mitochondrial function, activity of ALT and AST, protein and lipid metabolism in the liver as well as overall health. Well-developed networks of reticular and collagen fibres in hepatic lobules are indicative of normal liver morphology.

In a study by Butler et al. (1996), lupine alkaloids exerted negative effects on liver 
physiology and function in rats given diets containing lupine (Lupinus angustifolius) alkaloids at 250,1 050 and $5050 \mathrm{mg} / \mathrm{kg}$ body weigh. The cited authors observed changes in blood morphology, a decrease in liver weight with increasing alkaloid doses, and pathomorphological changes in the liver.

The effects of feeding blue lupine seeds as a vegetable protein source in rat diets were negative. The use of diets containing $0.09,0.11$ and $0.15 \mathrm{~g}$ alkaloids per $\mathrm{kg}$ reduced feed intake, thus limiting the growth rate of rats. Changes in the analyzed biochemical blood indicators and, more importantly, histopathological changes in the liver of rats, observed in the study, indicate that the use of blue lupine seeds as a protein source in animal diets is determined by factors such as the alkaloid content of lupine seeds and age-related responses of animals to the presence of alkaloids in feed.

\section{Acknowledgements}

The study was conducted as part of the statutory research project No. 528-01-02-0802. The equipment used in the study (Varian 450-GC Gas Chromatograph, 220-MS Mass Spectrometer) was purchased under the Operational Programme "Development of Eastern Poland", 2007-2013, European Union, European Regional Development Fund.

\section{References}

Bañuelos Pineda J, Nolasco Rodríguez G, Monteon JA, García López PM, Ruiz Lopez MA, García Estrada J 2005: Histological evaluation of brain damage caused by crude quinolizidine alkaloid extracts from lupines. Histol Histopathol 20: 1147-1153

Birk Y 1993: Antinutritional factors ANFs in lupin and in other legume seeds: pros and cons. In: Proceedings of the 7th International Lupin Conference, Evora, Portugal, pp. 424-429

Butler WH, Ford GP, Creasy DM 1996: A 90-day feeding study of lupin (Lupinus angustifolius) flour spiked with lupin alkaloids in the rat. Food Chem Toxicol 34: 531-536

Close B, Banister K, Baumas V, Bernoth EM, Bromage N, Bunyan J, Erhardt W, Flecknell P, Gregory N, Hackbarth H, Morton D, Warwick C 1997: Recommendations for euthanasia of experimental animals. Part 2. Lab Animals 31: 1-32

Crepon K, Marget P, Peyronnet C, Carrouee B, Arese P, Duc G 2010: Nutritional value of faba bean (Vicia faba L.) seeds for feed and food. Field Crop Res 115: 329-339

De Cortes-Sánchez M, Altares P, Pedrosa MM, Burbano C, Cuadrado C, Goyoaga C, Muzquiz M, JiménezMartínez C, Dávila-Ortiz G 2005: Alkaloid variation during germination in different lupin species. Food Chem 90: $347-355$

Directive 2010/63/EU of the European Parliament and of the Council of September 2010 on the protection of animals used for scientific purposes. Official Journal of the European Union, OJ L 276, 2010, p. 33-79

Gdala J, Buraczewska L 1996: Chemical composition and carbohydrate content of seeds from several lupin species. J Anim Feed Sci 5: 403-416

Hedemann M S, Eskildsen M, Lærke HN, Pedersen C, Lindberg J E, Laurinen P, Bach Knudsen K E 2006: Intestinal morphology and enzymatic activity in newly weaned pigs fed contrasting fiber concentrations and fiber properties. J Anim Sci 84: 1375-1386

Juśkiewicz J, Godycka-Kłos I, Matusevicius P, Zduńczyk Z, Juśkiewicz M 2006: Influence of pea and lupin oligosaccharides on caecal short-chain fatty acids production and nitrogen excretion patterns in rats. Pol J Food Nutr Sci 1:77-82

Lampart-Szczapa E, Łoza A 2007: Functional components of lupine seeds - opportunities and potential threats (in Polish). Zeszyty Problemowe Postępów Nauk Rolniczych 522: 387-392

Liberati TA, Sansone SR, Feuston MH 2004: Hematology and clinical chemistry values in pregnant Wistar Hannover rats compared with nonmated controls. Vet Clin Pathol 33: 68-73

Madej J A, Rotkiewicz T 2006: General Veterinary Pathology (in Polish). University of Warmia and Mazury, Olsztyn, 412 p.

Maknickiene Z, Asakaviciute R, Baksiene E, Razukas A 2013: Alkaloid content variations in Lupinus luteus L. and Lupinus angustifolius L. Arch Biol Sci Belgrade 65: 107-112

National Research Council 1995: Nutrient Requirements of Laboratory Animals, $4^{\text {th }}$ edn. National Academy Press, Washington, DC, $176 \mathrm{p}$.

Rahman MH 2005: Hypocholesterolemic activity of lupin proteins - A serendipitous discovery, In: Optimised processes for preparing healthy and added value food ingredients from lupin kernels, the European protein-rich grain legume. Proceedings of the Final Conference of the European Project, Milan, 9-10 November 2005, pp. 199-202

Robbins MC, Petterson DS, Brantom PG 1996: A 90-day feeding study of the alkaloids of Lupinus angustifolius in the rat. Food Chem Toxicol 34: 679-686 
Rotkiewicz T 2004: Pathomorphology of animal cells and tissues (in Polish). University of Warmia and Mazury, Olsztyn, $200 \mathrm{p}$.

Rotkiewicz T, Stanek M, Wiśniewska M, Otrocka-Domagała I, Bogusz J, Purwin C, Bomba G 2007: Pathomorphological and histochemical examinations of the digestive tracts and some internal organs of pigs fed diets containing narrow-leaved lupin (Lupinus angustifolius) seeds. Ann Anim Sci 7: 83-88

Saini HS 1989: Legume seed oligosaccharides. In: Huisman J, van der Poel TFB, Liner JE (Eds): Recent advances of research in antinutritional factors in legume seeds. Pudoc, Wageningen, pp. 329-341

Sobotka W, Stanek M, Bogusz J, Matusevicius P 2013: The effect of oligosaccharides and alkaloids contained in yellow and blue lupine seeds on feed intake, body weight and fermentation processes in the cecum of rats. Vet Zootech-Lith 63: 63-70

Stanek M, Bogusz J, Sobotka W, Bieniaszewski T 2006: Nutritive value of new varieties of yellow lupine (Lupinus luteus) and narrow-leaved lupine (Lupinus angustifolius). Ann Anim Sci 2/1: 206-210

Stanek M, Bogusz J, Sobotka W, Bieniaszewski T 2012: Nutritional value of blue lupine seeds (in Polish). Fragm Agron 29: 160-166

Zawistowski S 1975: Histological technique, histology and fundamentals of histopathology (in Polish). State Beetingmedical Publications, Warszawa 518 p. 
Plate I

Stanek M. et al.: The effect o alkaloids... pp. 55-62

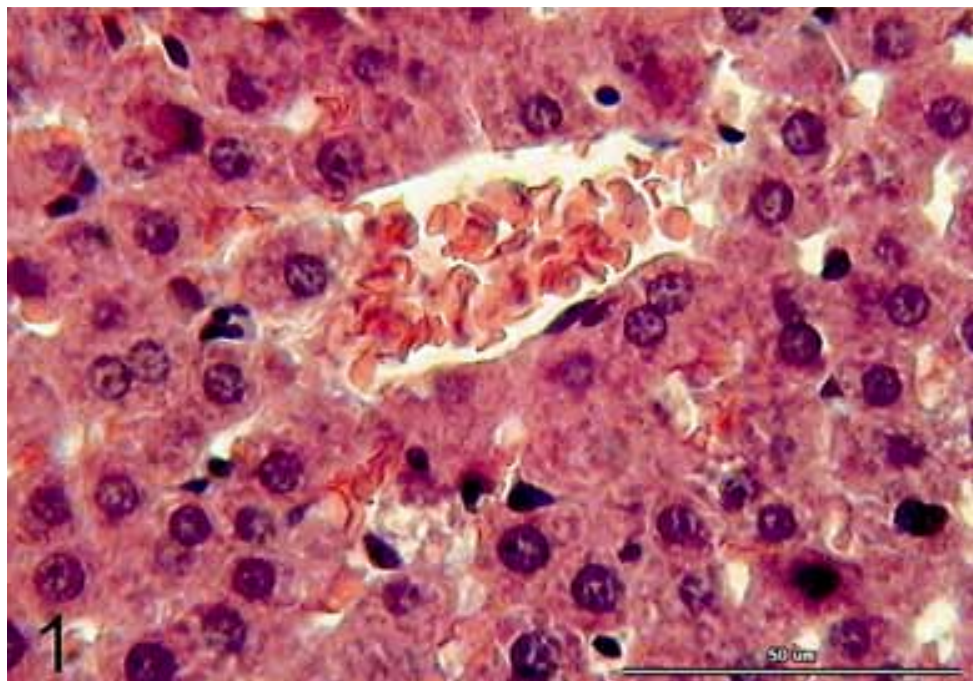

Fig. 1. Congestion of the central vein of a hepatic lobule and well-developed hepatocytes in the liver of a control group rat. Haematoxylin and eosin stain.

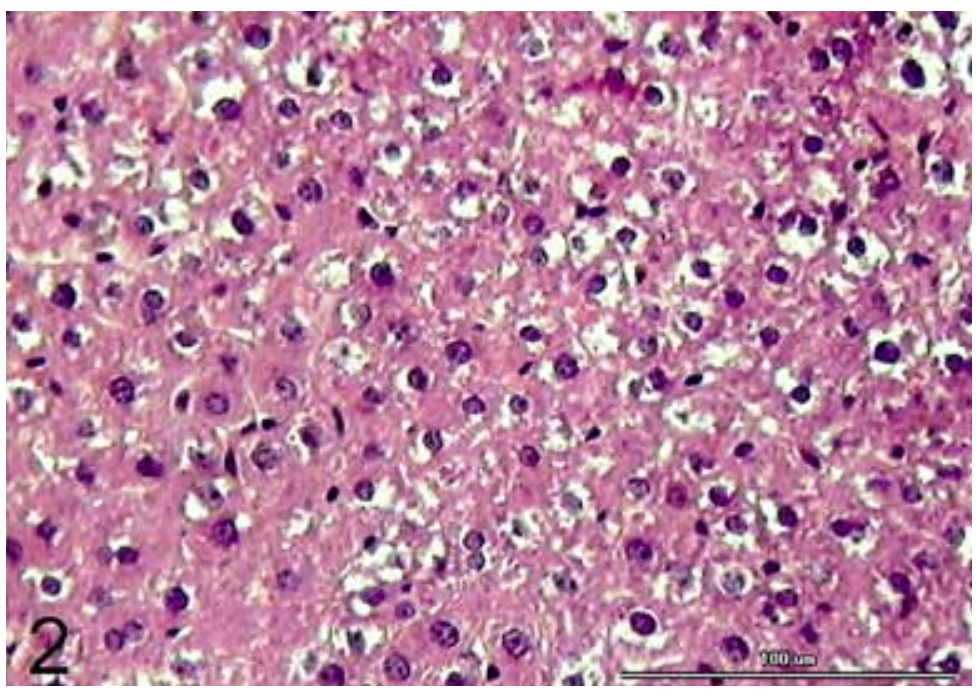

Fig. 2. Parenchymatous degeneration of hepatocytes and a few hepatocytes with signs of vacuolar degeneration in the liver of a rat fed a diet with a low alkaloid content. Haematoxylin and eosin stain. 


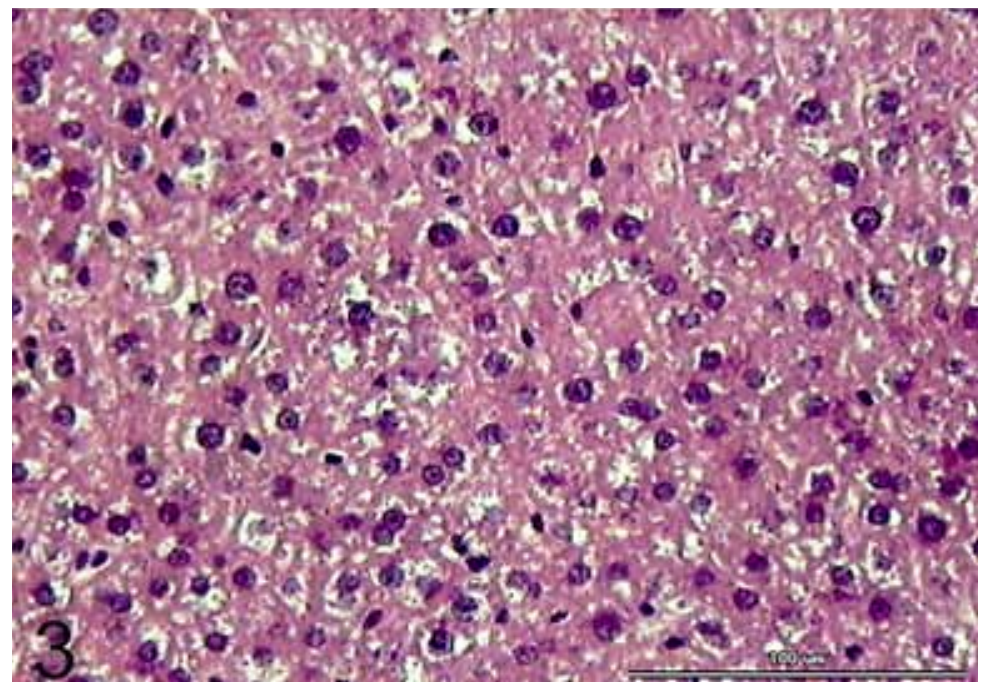

Fig. 3. Parenchymatous and vacuolar degeneration of hepatocytes in the liver of a rat fed a diet with a medium alkaloid content. Haematoxylin and eosin stain.

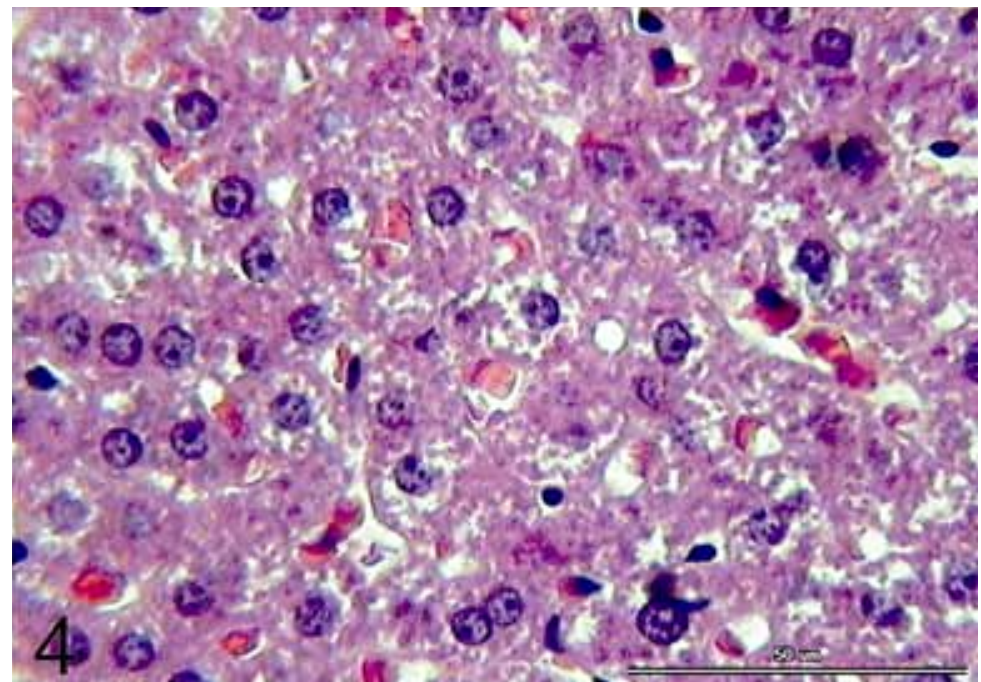

Fig. 4. Parenchymatous and vacuolar degeneration of hepatocytes in the liver of a rat fed a diet with the highest alkaloid content. Haematoxylin and eosin stain. 